\title{
Overseeing research integrity
}

\author{
The UK research establishment needs to ensure that there is a clear, transparent process for reporting and \\ investigating accusations of scientific misconduct.
}

E ditorials are not usually front-page news, but a recent editorial comment from Dr. Fiona Godlee, editor in chief for the British Medical Journal (BMJ), has been creating waves in the UK. The BMJ has been at the forefront of investigating Andrew Wakefield's (now retracted) Lancet paper that suggested a link between the MMR vaccine and autism, and earlier this year, the journal concluded that Wakefield's publication was not only scientifically incorrect, but that it could be "an elaborate fraud". Accordingly, it called on University College London (UCL), which has since taken over the Royal Free hospital where Wakefield carried out his research, to establish an enquiry. Although UCL has assured the journal of a through investigation, it has not yet publicly released the details of its investigation. The BMJ has now taken the unusual step of calling on the UK parliamentary select committee on Science and Technology to head the investigation, on the basis that the UCL's response to accusations of scientific fraud is inadequate and that there may be an institutional conflict of interest (http://tinyurl.com/6va7q3d). The committee declined, arguing that such an investigation was not within its remit and that it did not have the necessary expertise.

One could argue that Dr. Wakefield's work is of greater public interest than many other investigations of possible scientific misconduct, but the current controversy highlights the fact that such investigations are not always straightforward and that there is no clear process for escalating investigations at the supra-institutional level in the UK. In most cases, the responsibility for investigating accusations of research misconduct falls almost entirely on the individual institutions in which the research was carried out, with no rules in place compelling reporting to an external, publicly funded body. In the vast majority of cases, an institutional investigation of potential misconduct is sufficient to resolve matters satisfactorily. UK institutions can also receive guidance on good research practice and how to address fraud and misconduct from the UK Research Integrity Office (UKRIO, http://www.ukrio.org/). However, the UKRIO is not a regulatory body and has no formal legal powers. Moreover, although funding bodies such as the Wellcome Trust do, in theory, have the power to undertake their own investigations in exceptional circumstances, publicly available information about any investigations (whether by research institutions or by funding bodies) is scarce.

The lack of a single, universally recognized organization with a formal mandate to handle research integrity issues means that not all researchers are necessarily well-informed about these issues. According to Prof. Russell Foster at the University of Oxford and a member of UKRIO, "Would the average lab scientist in the UK know what to do if $s /$ he has any concerns about research misconduct? The answer is no. In contrast with issues such as animal work, for example, where grant applications require that researchers confirm that they've read and understood specific policies about how to do animal work, many funding bodies do not have a similar requirement that applicants confirm that they are aware of how to deal with research integrity issues." The Wakefield investigation also highlights the fact that there is no clear procedure for what the next step might be if an institutional investigation is felt to be insufficient. This is a concern shared by those who are ultimately in charge of deciding on taxpayer funding for research; earlier this year, a parliamentary Science and Technology committee report (http://tinyurl.com/3nsp2mu) expressed concern that the UK does not seem to have an oversight body for research integrity that provides "advice and support to research employers and assurance to research funders, across all disciplines".

Unfortunately, the recommendations of this report have so far been largely ignored by the research community, which is a shame. Moreover, although most UK research institutions do provide training and information on research ethics as part of their legal obligation, which makes them responsible for the conduct of their employees, more needs to be done to ensure that all working scientists are aware of the existence of external advisory bodies such as UKRIO and that they have a clear idea of exactly what steps need to be taken to tackle any concerns that arise. In particular, grant funding bodies need to ensure that all of their applicants are aware of guidelines for good research practice and the procedure for addressing any concerns. An additional 'tick box' on grant funding applications to ensure that the applicants are aware of their options in this area is a good first step, but, ultimately, the establishment of a statutory regulatory body with formal legal powers that sets out clear guidelines, as suggested by the parliamentary report, may be necessary to ensure that there is no institutional conflict of interest and that there is a transparent process to ensure accountability.

Crucially, investigations of research misconduct should be as transparent as possible, especially for research on contentious issues that have a clear effect on public health. Scientists must be keenly aware that accusations of research misconduct are particularly harmful for public perception of research; the current popular discourse on climate change is an indication of how easily opinion can be swayed by the mere suggestion of scientific fraud. This is particularly important in the current economically strained times, and scientists need to demonstrate that issues of research integrity are approached with the same rigor that is applied to scientific work itself, where open discussions are the norm. Although the UK research community has largely been spared the anguish caused by recent high-profile cases of large-scale fraud that potentially brings a whole body of research into disrepute, this state of affairs cannot be taken for granted. The community needs to continue discussions of how best to meet the ethical challenges of research in an increasingly competitive environment to ensure that its justifiable reputation for world-class research is maintained. 